\title{
CORRELATION OF CLIMATE VARIABILITY AND MALARIA: A RETROSPECTIVE COMPARATIVE STUDY, SOUTHWEST ETHIOPIA
}

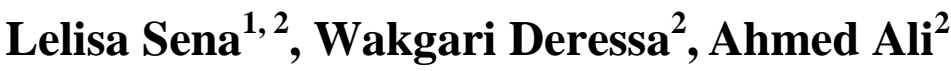

\begin{abstract}
BACKGROUND: Climatic variables can determine malaria transmission dynamics. To see the correlation between malaria occurrence and climatic variables, records of malaria episodes over eight years period were analyzed incorporating climatic variables around Gilgel-Gibe Hydroelectric Dam and control sites.

METHODS: Records of 99,206 confirmed malaria episodes registered between 2003 and 2011 were analyzed along with local meteorological data of the same duration. Data were analyzed with SPSS statistical software version 20 for Windows. Spearman correlation coefficient was estimated as a measure of the correlation.

RESULTS: The major peaks of malaria prevalence were observed following the peaks of rainfall in the Gilgel-Gibe Hydroelectric Dam site. In the control site, the peaks of malaria in some years coincided with the peaks of rainfall, and the pattern of rainfall was relatively less fluctuating. Mean rainfall was negatively correlated with number of malaria cases at lags of 0 and 1 month, but positively correlated at lags of 2 to 4 months. Mean relative humidity showed significant positive correlations at lags of 3 to 4 months. Monthly mean maximum and minimum temperatures weakly correlated at lags of 0 to 4 months. CONCLUSIONS: Correlations of malaria and climate variables were different for the two sites; in Gilgel-Gibe, rainfall and relative humidity showed positive correlations. However, in the control site, the correlation of weather variables and malaria episodes were insignificant. Exploration of additional factors such as vegetation index and physico-chemical nature of mosquito breeding site may improve understanding of determinants of malaria dynamics in the area.
\end{abstract}

KEYWORDS: climatic variables, correlations, Ethiopia, Gilgel-Gibe, malaria

DOI: http://dx.doi.org/10.4314/ejhs.v25i2.5

\section{INTRODUCTION}

Malaria has been a major public health problem and a hindrance to socioeconomic development in Ethiopia (1). Clear knowledge of the driving factors of malaria dynamics in a particular area is crucial for better planning and implementation of prevention and control strategies (2). Trends of malaria and composition of Plasmodia species vary over time (3-6) due to different factors such as previous climatic factors. Climatic variables determine the dynamics of malaria by limiting the survival and longevity of malaria vectors and the rate of Plasmodium development in the vector mosquitoes $(3,7-10)$.

Some studies underlined that climatic variables partially or fully (11-13) correlated positively with monthly incidence of malaria, whereas others reported different levels of correlation of climatic variables with malaria occurrence in different eco-epidemiological settings (14-16). Brooker et al (17) emphasized that the distribution of malaria is determined by

\footnotetext{
${ }^{1}$ Department of Epidemiology, College of Public Health and Medical Sciences, Jimma University, Ethiopia

${ }^{2}$ Department of Preventive Medicine, School of Public Health, College of Health Sciences, Addis Ababa

University, Ethiopia

Corresponding Author: Lelisa D Sena, Email: lelisajitu@gmail.com
} 
climatic and other geographic factors that affect vector mosquito and Plasmodium reproduction. However, still other findings show neither association between the number of malaria cases (18) nor trend of malaria vector populations and climatic variables.

Environmental factors such as changing rainfall patterns, water development projects and unusual temperature increase can play great roles in malaria transmission dynamics (19). Moreover, anthropogenic disruption of the natural equilibrium of environment inevitably modifies the malaria transmission dynamics $(20,21)$. Thus, understanding how malaria varies in a particular area as a result of changes in environmental factors is of paramount importance for the planning of malaria control programs (22). However, the transmission pattern of malaria with climatic variables is less studied in a modified environment, due to human activities, relative to an unaffected area. In this regard, this study assessed and compared trends of malaria for two sites-villages surrounding a hydroelectric power dam (GGHD) and similar control villages without a dam. The study incorporated climatic variables (temperature, precipitation and relative humidity) to see whether these variables play a role in the pattern of malaria prevalence in those sites differently.

\section{MATERIALS AND METHODS}

Study settings: This retrospective record review comparative study was conducted in two rural settings: one site near a manmade lake, GGHD, and a control site from an area far from the Lake. Gilgel Gibe Hydroelectric Dam (GGHD) is located $260 \mathrm{~km}$ south-west of Addis Ababa, the capital of Ethiopia. On global positioning, the dam is found at $07.4253^{\circ}$ to $07.5558^{\circ} \mathrm{N}$ and $037.1153^{\circ}$ to $037.2033^{\circ} \mathrm{E}$. The area lies within the range of mosquito breeding altitude. Surveys conducted in the area (23-25) have shown that the prevalence of malaria among children was higher by many folds than the national malaria indicator survey results of 2007 (26).

From Kersa District, where the control site selected, only two kebeles (smallest administrative units) are found within $10 \mathrm{~km}$ radius of the GGHD, and those villages (Dogoso and Siba) were considered to be influenced by the Dam.
Thus, they were included to the study villages of GGHD. Twenty-seven other kebeles (villages) of Kersa District, excluding Dogoso and Siba, are malarious of which 21 are labeled as high risk villages and eight of these high risk kebeles designated as control site. A previous study also indicated that the prevalence of malaria was high in the control site (27). Like GGHD areas, all those villages have health posts staffed with health extension workers; the residents had similar living patterns. Additional description of the study sites was given elsewhere (28) and figure 1 shows the position of the study sites, including small towns in them.

Study design: A retrospective record review of malaria episodes and meteorological data of the same duration were carried out. Monthly malaria morbidity records registered between September 2003 and August 2011 in local health facilities pertaining to villages within 10-kilometer radius of GGHD and in those health facilities of the control sites were analyzed along monthly average climatic variables. The monthly means of both minimum and maximum temperatures, relative humidity and rainfall of local meteorological stations of the two sites were incorporated into the analysis to examine the correlations of malaria and climate variability over the eight years period. As major changes in malaria transmission had been recorded to have occurred in periodic cycle of between 5 and 8 years in the country $(14,29)$, the time for this study was limited to eight years.

Source of data and sample size: There were eight health posts and three health centres in the GGHD site. In the control site, there were also eight health posts and a health centre. The malaria episodes data were collected from those health institutions within the catchments of GGHD and the control sites. All malaria episode records kept in the health institutions between September 2003 and August 2011 were reviewed. The meteorological data (temperature, humidity and precipitation) of the study sites were sought from the National Meteorological Agency South West Ethiopia Regional Branch.

Data collection techniques: Format was prepared on a computer spreadsheet (excel) to collect secondary data from health institutions of the designated sites. Individual level data on malaria morbidity and mortality were collected from logbooks of the local health institutions. Variables 
such as diagnosis results (negative, species of Plasmodium for positives), dates of diagnosis and available demographic data (residence, age, sex) were captured on the computer spreadsheet. All records of patients who visited health institutions and were treated as malaria patients were included in the study. Records of cases with incomplete or invisible records such as dates of health service visit, age, address, results of diagnosis were excluded from the study.

Data management and processing: Initially, patient records kept in logbooks at the health institutions were recorded on excel spreadsheet separately. Then, data on patient records from different health institutions were checked for completeness, coded and combined on the same spreadsheet. Only a few incomplete records were discarded from the analysis. Daily minimum and maximum climate variables (temperatures, precipitation and relative humidity) were recorded on a computer spreadsheet separately for GilgelGibe and the control sites. For both localities, monthly averages of climatic variables were computed for minimum, mean and maximum values. Then, prepared data of malaria episodes and meteorological data were exported to SPSS statistical software version 20 for Windows and linked together using unique identifiers (month, year and location codes). Then, analyses were performed using Spearman correlation coefficient. The graphic presentation of rainfall of the sites against monthly malaria episodes was done with excel.

Ethical considerations: Ethical clearances were obtained from the Addis Ababa University College of Health Sciences Institutional Review Board and the Oromia Regional Health Bureau Ethical Clearance Committee. South-West
Regional Branch Meteorological Agency, Jimma Zonal Office and district health offices as well as local administrators were requested through formal letters from the School of Public Health of Addis Ababa University and Oromia Regional Health Bureau for their cooperation and consents. Individual information was kept confidential and the names of individuals were removed from data of health services and identified only by identification numbers. Results were also communicated in an aggregated manner.

\section{RESULTS}

A total of 99,206 confirmed malaria episodes were recorded over eight years period in both study sites. More than two-third (71.8\%) of the episodes were from the control site, while $28.2 \%$ of them were from Gilgel-Gibe. In spite of inter annual variations, proportion of $P$. falciparium slightly increased over time in GGHD site; however, the $P$. falciparium proportion significantly decreased relative to $P$. vivax in the control sites (Table 1).

Eight years monthly averages of maximum, mean, and minimum climatic variables of the study sites are summarized in table 2 . The average maximum rainfall of the control site was higher than the GGHD site (20.2 $\mathrm{mm}$ vs $10.7 \mathrm{~mm}$ ), whereas the average mean rainfall was similar in both sites with same standard deviations. The average mean relative humidity of the control site was slightly higher than that of GGHD site. However, the means of maximum and minimum relative humidity of both study sites were the same. On the other hand, both means of maximum and minimum temperatures were slightly higher in control sites, with higher variability of the latter (SD: 2.7 vs 2.0 ) in the control site (Table 2). 
Table 1: Distribution of confirmed malaria cases by study sites, Plasmodium species and years of health service visits, southwest Ethiopia, September 2003 to August 2011

\begin{tabular}{|c|c|c|c|c|c|c|c|c|c|c|c|c|}
\hline Sites & Species & & 2003 & 2004 & 2005 & 2006 & 2007 & 2008 & 2009 & 2010 & 2011 & Total \\
\hline \multirow{7}{*}{ 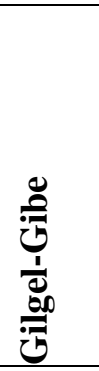 } & \multirow[b]{2}{*}{$\mathrm{PF}$} & No & 910 & 665 & 443 & 571 & 2116 & 3762 & 5432 & 2271 & 759 & 16929 \\
\hline & & $\%$ & 48.8 & 47.9 & 61.0 & 52.6 & 56.0 & 63.3 & 74.2 & 50.4 & 54.0 & 60.4 \\
\hline & \multirow[b]{2}{*}{ PV } & No & 328 & 587 & 237 & 443 & 1619 & 2177 & 1825 & 1752 & 442 & 9410 \\
\hline & & $\%$ & 17.6 & 42.3 & 32.6 & 40.8 & 42.9 & 36.6 & 24.9 & 38.9 & 31.4 & 33.6 \\
\hline & \multirow{2}{*}{ PM } & № & 627 & 136 & 46 & 71 & 43 & 7 & 63 & 482 & 205 & 1680 \\
\hline & & $\%$ & 33.6 & 9.8 & 6.3 & 6.5 & 1.1 & 0.1 & 0.9 & 10.7 & 14.6 & 6.0 \\
\hline & Subtotal & No & 1865 & 1388 & 726 & 1085 & 3778 & 5946 & 7320 & 4505 & 1406 & 28019 \\
\hline \multirow{7}{*}{ ن⿺辶大 } & \multirow[b]{2}{*}{$\mathrm{PF}$} & No & 1640 & 3006 & 6286 & 2557 & 5315 & 6669 & 5443 & 6275 & 43 & 37234 \\
\hline & & $\%$ & 76.5 & 61.2 & 54.2 & 58.6 & 53.0 & 48.4 & 53.0 & 45.0 & 23.2 & 52.3 \\
\hline & \multirow{2}{*}{ PV } & No & 467 & 1826 & 5096 & 1733 & 4493 & 6785 & 4593 & 6696 & 140 & 31829 \\
\hline & & $\%$ & 21.8 & 37.2 & 44.0 & 39.7 & 44.8 & 49.3 & 44.7 & 48.1 & 75.7 & 44.7 \\
\hline & \multirow[b]{2}{*}{$\mathrm{PM}$} & No & 37 & 79 & 211 & 71 & 211 & 316 & 235 & 962 & 2 & 2124 \\
\hline & & $\%$ & 1.7 & 1.6 & 1.8 & 1.6 & 2.1 & 2.3 & 2.3 & 6.9 & 1.1 & 3.0 \\
\hline & Subtotal & № & 2144 & 4911 & 11593 & 4361 & 10019 & 13770 & 10271 & 13933 & 185 & 71187 \\
\hline \multirow{7}{*}{ बే } & \multirow{2}{*}{ PF } & No & 2550 & 3671 & 6729 & 312 & 7431 & 10431 & 10875 & 8546 & 802 & 54163 \\
\hline & & $\%$ & 63.6 & 58.3 & 54.6 & 57.4 & 53.9 & 52.9 & 61.8 & 6.3 & 50.4 & 54.6 \\
\hline & \multirow{2}{*}{ PV } & No & 795 & 2413 & 5333 & 2176 & 6112 & 8962 & 6418 & 8448 & 582 & 41239 \\
\hline & & $\%$ & 19.8 & 38.3 & 43.3 & 40.0 & 44.3 & 45.5 & 36.5 & 45.8 & 36.6 & 41.6 \\
\hline & \multirow{2}{*}{$\mathrm{PM}$} & No & 664 & 215 & 257 & 142 & 254 & 323 & 298 & 1444 & 207 & 3804 \\
\hline & & $\%$ & 16.6 & 3.4 & 2.1 & 2.6 & 1.8 & 1.6 & 1.7 & 7.8 & 13.0 & 3.8 \\
\hline & Total & № & 4009 & 6299 & 12319 & 5446 & 13797 & 19716 & 17591 & 18438 & 1591 & 99206 \\
\hline
\end{tabular}

PM: Plasmodium mixed; PF: plasmodium falciparum; PV: plasmodium vivax

The rainfall pattern in GGHD site showed several rises that lasted for short durations, whereas that of the control site exhibited a gradual rise and relatively minimal variations. At the GGHD site, the major peaks of malaria prevalence were observed following the peaks of rainfall. In the control site, the peaks of malaria prevalence in some years coincided with the peaks of rainfall, and the pattern of rainfall relatively fluctuated less and was almost continuous in quarters of the year. Between December 2007 and March 2008, rainfall reached the highest peak and malaria prevalence climax was noticed after the rainfall peak. It is evident from the linear trend line that malaria prevalence increased more in the GGHD site than in the control site, despite the higher malaria prevalence observed in the control site over the entire study period (Fig 1). 
Table 2: Monthly averages of eight years climatic variables of study sites, southwest Ethiopia, September 2003 to August 2011

\begin{tabular}{clccc}
\hline Weather variables & & $\begin{array}{c}\text { Gilgel-Gibe } \\
\text { Mean (SD) }\end{array}$ & $\begin{array}{c}\text { Control } \\
\text { Mean (SD) }\end{array}$ & $\begin{array}{c}\text { Overall } \\
\text { Mean (SD) }\end{array}$ \\
\hline Rainfall (mm) & Maximum & 11.9 & $20.2(3.6)$ & 20.2 \\
& Mean & $3.3(2.9)$ & $3.7(3.6)$ & $3.3(3.2)$ \\
\hline Relative humidity & Maximum & 76.7 & 76.8 & 76.8 \\
$(\mathrm{mmHg})$ & Mean & $54.2(12.7)$ & $55.8(11.9)$ & $55.2(12.2)$ \\
& Minimum & 24.7 & 24.7 & 24.7 \\
\hline Temperature $\left(\mathrm{C}^{\mathrm{o}}\right)$ & Maximum & $27.40(2.6)$ & $28.0(2.1)$ & $27.8(2.2)$ \\
& Mean & $19.3(1.2)$ & $19.9(1.1)$ & $19.6(1.2)$ \\
& Minimum & $11.2(2.0)$ & $11.8(2.7)$ & $11.5(2.5)$ \\
\hline
\end{tabular}

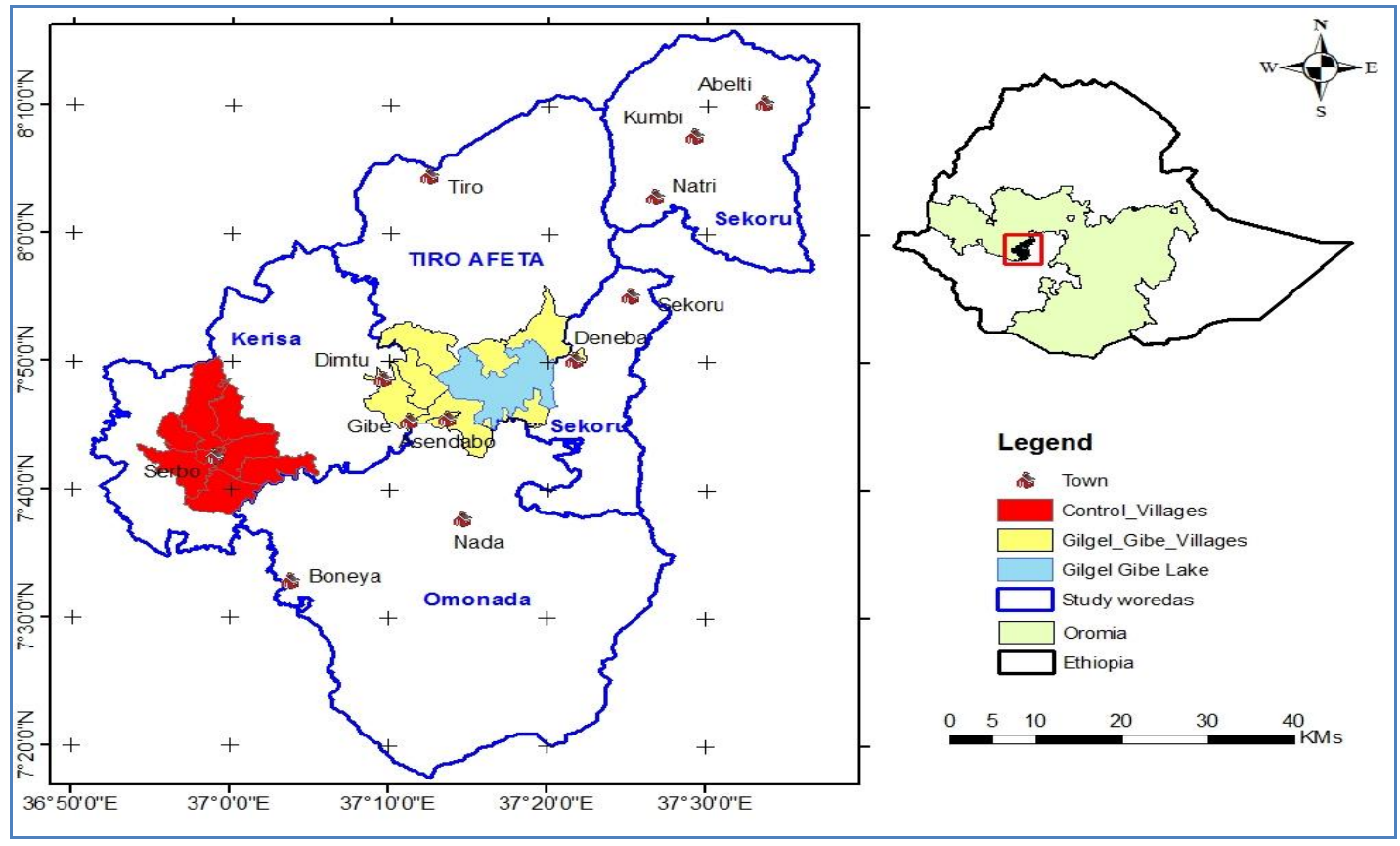

Figure 1: Map of the Study sites within Oromia Regional State of Ethiopia

Raw data source: CSA \& JU-IHSR

Monthly mean rainfall and number of monthly malaria cases showed negative correlation at lag of 0 and 1 month, but positive correlation at lags of 2 to 4 months. The correlation increased as the number of lags increased from 2 to 4 months although the positive correlation of rainfall with the number of malaria episodes was insignificant at all the lags. Monthly mean relative humidity showed positive correlation with number of malaria episodes from lag of 0 to 4 months and the strength of the correlation increased as the number of lags increased. There were significant correlations at lags of $3(\mathrm{P}=0.02)$ and $4(\mathrm{P}=0.03)$ months. Monthly average maximum temperature and the number of malaria episodes showed negative, but weak and insignificant correlation at all lags of 0 to 4 months. Again, monthly average minimum temperature exhibited a negative correlation with number of malaria episodes up to lags of 2 months, but positive correlation at lags of 3 and 4 months. The correlation was of incremental nature with number of lag months. However, the correlation was weak and insignificant (Table 3). 


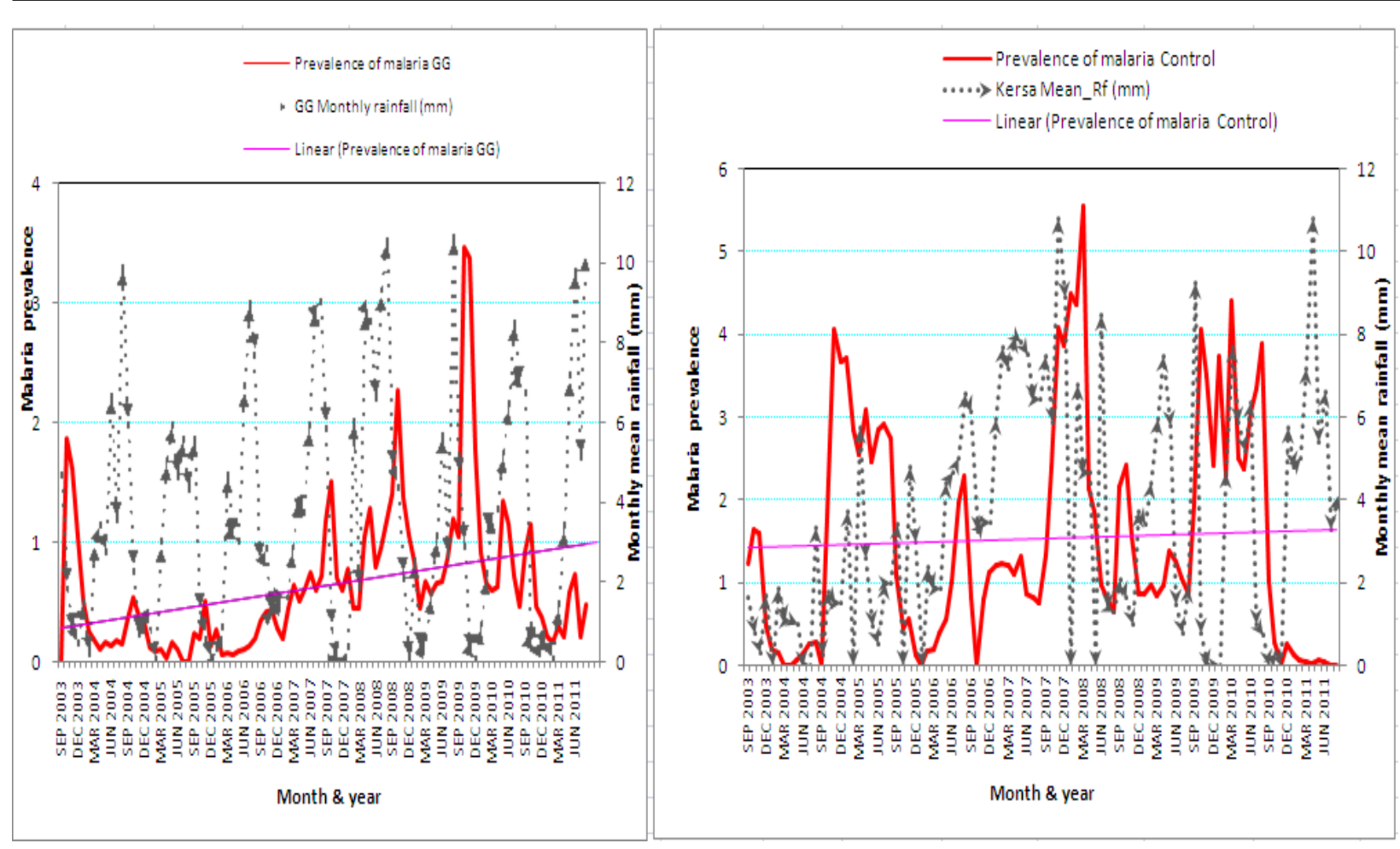

Figure 2: Prevalence of malaria and monthly mean rainfall by quarter and year, southwest Ethiopia, September 2003-August 2011.

Table 3 Correlation between monthly confirmed malaria episodes and mean monthly climatic variables by study sites, Southwest Ethiopia, September 2003-August 2011

\begin{tabular}{|c|c|c|c|c|}
\hline $\begin{array}{c}\text { Monthly mean } \\
\text { Climate variables }\end{array}$ & $\begin{array}{l}\text { Lag- } \\
\text { months }\end{array}$ & $\begin{array}{c}\text { Gilgel-Gibe } \\
\text { Spearman's r }\end{array}$ & $\begin{array}{c}\text { Control } \\
\text { Spearman's r }\end{array}$ & $\begin{array}{c}\text { Overall } \\
\text { Spearman's r }\end{array}$ \\
\hline \multirow{5}{*}{ Rainfall } & 0 Months & 0.0060 & -0.1959 & -0.076 \\
\hline & 1 Month & 0.1278 & -0.1473 & -0.003 \\
\hline & 2 Months & 0.3589 & -0.1495 & 0.065 \\
\hline & 3 Months & 0.3270 & -0.0806 & 0.078 \\
\hline & 4 Months & 0.2304 & 0.0494 & 0.108 \\
\hline \multirow{5}{*}{ Relative humidity } & 0 Months & 0.0133 & -0.2154 & 0.006 \\
\hline & 1 Month & 0.1591 & -0.1099 & 0.086 \\
\hline & 2 Months & 0.4182 & -0.0381 & 0.133 \\
\hline & 3 Months & 0.2820 & 0.0789 & 0.171 \\
\hline & 4 Months & 0.2174 & 0.1184 & 0.157 \\
\hline \multirow{5}{*}{ Maximum temperature } & 0 Months & -0.0983 & 0.1723 & -0.020 \\
\hline & 1 Month & -0.2044 & 0.0966 & -0.072 \\
\hline & 2 Months & -0.2350 & 0.0203 & -0.136 \\
\hline & 3 Months & -0.2233 & -0.0894 & -0.130 \\
\hline & 4 Months & -0.1874 & -0.1099 & -0.116 \\
\hline \multirow{5}{*}{ Minimum temperature } & 0 Months & -0.261 & -0.1108 & -0.123 \\
\hline & 1 Month & -0.0808 & -0.0611 & -0.052 \\
\hline & 2 Months & 0.0191 & -0.0535 & -0.031 \\
\hline & 3 Months & 0.1135 & 0.0441 & 0.001 \\
\hline & 4 Months & 0.1676 & 0.1027 & 0.039 \\
\hline
\end{tabular}


Similarly, there was a negative correlation between average number of monthly P. falciparum malaria cases and rainfall at 0 and 1 month lags, and positive, but weak correlation from 2 to 4 months lags. Relative humidity showed negative correlation at 0 month, positive and increasing correlation from 1 to 4 months lags. At the GGHD site, moderate correlations were observed at months 2 and 3 lags both with rainfall and relative humidity in Gilgel-Gibe site. There were only weak positive correlations at month 4 for rainfall and months 2 through 4 for relative humidity at the control site.
The maximum and minimum average temperatures were, in most cases, negatively and weakly correlated with the monthly number of $\mathrm{P}$. falciparum malaria episodes. The average minimum temperature was weakly but positively correlated in GGHD site from 1 to 4 months lags. In the control site, the average maximum temperature was positive, but insignificantly correlated with the monthly number of malaria episodes at lag of 0 months. The correlations were not apparent when combined for both sites and there were very weak correlations when analyzed for the two sites together (Table 4).

Table 4: Correlation between average monthly $P$. falciparum malaria episodes and mean monthly climate variables by study sites, southwest Ethiopia, September 2003-August 2011

\begin{tabular}{clccc}
\hline $\begin{array}{c}\text { Monthly mean } \\
\text { Climate variables }\end{array}$ & $\begin{array}{l}\text { Lag- } \\
\text { months }\end{array}$ & $\begin{array}{c}\text { Gilgel-Gibe } \\
\text { Spearman's r }\end{array}$ & $\begin{array}{c}\text { Control } \\
\text { Spearman's r }\end{array}$ & $\begin{array}{c}\text { Overall } \\
\text { Spearman's r }\end{array}$ \\
\hline \multirow{2}{*}{ Rainfall } & 0 Months & 0.0077 & -0.1400 & -0.0860 \\
& 1 Month & 0.1356 & -0.1004 & -0.0217 \\
& 2 Months & 0.3889 & -0.0936 & 0.0698 \\
& 3 Months & 0.3778 & -0.0155 & 0.1098 \\
& 4 Months & 0.2096 & 0.0938 & 0.1139 \\
\hline \multirow{2}{*}{ Relative humidity } & 0 Months & 0.0773 & -0.1812 & -0.0053 \\
& 1 Month & 0.1708 & -0.0295 & 0.1031 \\
& 2 Months & 0.2558 & 0.0662 & 0.1784 \\
& 3 Months & 0.2855 & 0.1682 & 0.2366 \\
Maximum & 4 Months & 0.1730 & 0.1885 & 0.2006 \\
\hline temperature & 0 Months & -0.0029 & 0.1018 & 0.0312 \\
& 1 Month & -0.0249 & -0.0136 & -0.0204 \\
& 2 Months & -0.1514 & -0.1028 & -0.1062 \\
& 3 Months & -0.1056 & -0.1865 & -0.1165 \\
Minimum & 4 Months & -0.0539 & -0.1627 & -0.0873 \\
\hline temperature & 0 Months & -0.2162 & -0.1190 & -0.1446 \\
& 1 Month & 0.0449 & -0.6549 & -0.0321 \\
& 2 Months & 0.0030 & -0.7122 & -0.0040 \\
& 3 Months & 0.0493 & -0.6157 & 0.0640 \\
\hline
\end{tabular}

\section{DISCUSSION}

This study examined the correlation between three major climatic variables which are known to affect the dynamics of malaria (rainfall, relative humidity and temperature) and both monthly number of all types of confirmed malaria as well as $P$. falciparium malaria. Although the GGHD site is situated at slightly lower altitude range, both sites are found within malaria risk altitude ranges $(24,27)$, the number of malaria cases was higher in the control site possibly due to plenty of rainfall over the period considered compared to GGHD site. The correlation of persistent malaria transmission with such continuous higher level of rainfall is in agreement with the prediction model of malaria transmission in Africa $(20,30)$. However, it is inconsistent with the finding of a 
local study that reported that risk of malaria was found to be higher at lower altitude (31).

Overall monthly mean rainfall showed positive, but weak, correlation at lag-months 2 to 4 , and relative humidity has shown also a weak positive correlation from 0 to 4 months lag which is similar to estimated epidemic prediction of 2 to 4 months after rainfall in East Africa (32). However, when separately analyzed by study site, both rainfall and relative humidity were positively correlated with episodes of malaria in the GGHD, whereas negative correlation was observed in the control site up to three-months lag for rainfall, two-months lag for relative humidity, a month lag for minimum temperature and 0 to 4 months lag of maximum temperature. Such negative correlation of temperature and occurrence of malaria cases was reported by another study as well (33). The site-specific correlation of malaria prevalence and climate variables at different time lags in different eco-epidemiological settings were also indicated by other studies $(14,15,34,35)$. On the other hand, the absence or weak correlation of the climate variables with malaria occurrence was highlighted by certain studies $(18,36)$, whereas still other studies underline the strong correlation of climate variables with number of malaria cases $(11,12,37-40)$. The modest correlation of rainfall and relative humidity with episodes of malaria in the GGHD site was at two to three months lag which was congruent to a local study (41). Other studies reported correlations of shorter lags (42, 43); however, another local study had indicated more time lags (14).

Furthermore, other studies (44-46) indicated that the dynamics of malaria is determined by multiple contributing factors; the correlation between malaria and climatic variables is not always a direct one, and reliance on only climatic variables for prediction of malaria occurrence may not be sufficient. The correlation between climate variables and malaria episodes simply indicates the presence of a linear relationship between them, but the absence of correlation does not prove the absence of association of climate variables with occurrence of malaria. In a setting where minimal variability of temperature prevails and existing conditions are favorable for malaria, it may be difficult to distinguish the role of fluctuation of climatic parameters on malaria prevalence (16). Moreover, eco-epidemiological variability and species of malaria vector difference in different settings impose additional uncertainty on the generalizability of findings to other settings. Therefore, consideration of local specific factors is important in the battle against malaria.

Possible limitations of this study were use of some data from nearby stations and use of imputation methods where missing of data were encountered. Temperature and humidity data for the control site were obtained from Jimma Station, and for the GGHD site, humidity data of Sokoru Station were used. Both Jimma and Sokoru stations are close to the control and the GGHD study sites respectively. Thus, they are expected to have similar weather conditions as there is no major geographical difference in terms of altitude and coverage of vegetation between those stations and the respective study sites. In addition, imputation method was used to fill the missed humidity data of three years using the average of the respective months. Those conditions might affect the findings of this study to a certain extent.

In conclusion, correlations of malaria and climate variables were different for the two sites. In Gilgel-Gibe, rainfall and relative humidity showed positive correlations and modest correlations were seen during 2 to 3 months lags. In the control area, insignificant positive correlation of rainfall and relative humidity was noticed at 4 months and 3 to 4 months lags respectively. Mean maximum and minimum ambient temperature indicated weak correlations in both sites. This implies that in Gilgel-Gibe, rainfall and relative humidity are driving forces behind malaria at 2 to 3 months lags. On the other hand, the weak/absence of correlation does not prove absence of the association between malaria and climate variables; it simply implies absence of linear relationship between them. There is a need to consider additional factors such as a normalized difference vegetation index (NDVI) and the physico-chemical nature of the water bodies (mosquitoes breeding sites) in assessing malaria risk factors of a locality that play a role in the ratelimiting of the dynamics of malaria.

\section{ACKNOWLEDGEMENTS}

We are grateful to local health managers, data collectors and supervisors. Addis Ababa 
University is greatly acknowledged for funding the study. We greatly acknowledge the National Meteorological Agency South West Ethiopia Regional Branch for providing us the meteorological data.

\section{REFERENCES}

1. Taye B. Willingness to Pay for InsecticideImpregnated Bed Nets: The Case of Selected Rural Kebeles in Ilu Woreda of Western Shoa Zone. Ethiop J Econ, 2002;XI(1):1-32.

2. Kochar D.K. SP, Kochar S.K., Budania M.P. \& Lakhotia J.P. Dynamics of malaria in Bikaner, Rajasthan, India (1975-2006) J Vector Borne Dis, 2007;44:281-4.

3. Konchom S, Singhasivanon P, Kaewkungwal J, et al. Trend of malaria incidence in highly endemic provinces along the Thai borders, 1991-2001. Southeast Asian J Trop Med Public Health, 2003;34(3):486-94.

4. Fouque F, Gaborit P, Carinci R, Issaly J, Girod R. Annual variations in the number of malaria cases related to two different patterns of Anopheles darlingi transmission potential in the Maroni area of French Guiana. Malar J, 2010;9:80.

5. Srivastava HC, Bhatt RM, Kant R, Yadav RS. Malaria associated with the construction of the Sardar Sarovar Project for water-resources development, in Gujarat, India. Ann Trop Med Parasitol, 2009;103(7):653-7.

6. Zhou G, Afrane YA, Vardo-Zalik AM, et al. Changing Patterns of Malaria Epidemiology between 2002 and 2010 in Western Kenya: The Fall and Rise of Malaria. PLoS ONE, 2011;6(5):e20318.

7. Keiser J, Castro MCD, Maltese MF, et al. The effect of irrigation and large dams on the burden of malaria on global and regional scale. Am J Tr Med Hyg, 2005;72(4):392-406.

8. Thomson AJ. Climate indices, rainfall onset and retreat, and malaria in Nigeria. $J$ Vector Borne Dis, 2010 Dec;47(4):193-203.

9. Lieshout Mv, Kovats RS, Livermore MTJ, Martens P. Climate change and malaria: analysis ofthe SRES climate and socio-economic scenarios. Global Environmental Change, 2004;14:87-99.

10. Paaijmans KP, Read AF, Thomas MB. Understanding the link between malaria risk and climate. Ecology, 2009;106(33):13844-9.

11. Li T, Yang Z, Wang M. Temperature, relative humidity and sunshine may be the effective predictors for occurrence of malaria in Guangzhou, southern China, 2006-2012. Parasites \& Vectors, 2013;6:155.
12. Devi NP, Jauhari RK. Meteorological variables and malaria cases based on 12 years data analysis inDehradun (Uttarakhand) India. Europ J Exp Biol, 2013;3(1):28-37.

13. Omonijo AG, Matzarakis A, Oguntoke O, Adeofun CO. Influence of Weather and Climate on Malaria Occurrence Based on Human-Biometeorological Methods in Ondo State, Nigeria. J Env Sci Eng, 2011;5:1215-28.

14. Teklehaimanot HD, Lipsitch M, Teklehaimanot A, Schwartz J. Weather-based prediction of Plasmodium falciparum malaria in epidemic-prone regions of Ethiopia I. Patterns of lagged weather effects reflect biological mechanisms. Malar J, 2004;3:41.

15. Tay SCK, Danuor SK, Mensah DC, et al. Climate Variability and Malaria Incidence in Peri-urban, Urban and Rural Communities Around Kumasi, Ghana: A Case Study at Three Health Facilities; Emena, Atonsu and Akropong. Int J Parasitol Res, 2012;4(2):83-9.

16. Small J, Goetz SJ, Hay SI. Climatic suitability for malaria transmission in Africa, 1911-1995. PNAS, 2003;100(26):15341-5.

17. Brooker S LT, Kolaczinski K, Mohsen E, Mehboob N, Saleheen S, Khudonazarov J, Freeman T, Clements A, Rowland $\mathrm{M}$, and Kolaczinski J. Spatial Epidemiology of Plasmodium vivax, Afghanistan. Emerg Infect Dis, 2006;12(10):1600-2.

18. Haque U, Hashizume M, Glass GE, Dewan AM, Overgaard HJ, Yamamoto T. The Role of Climate Variability in the Spread of Malaria in Bangladeshi Highlands. PLOS ONE, 2010;5(12):e14341.

19. Nchinda CT. Malaria: A Reemerging Disease in Africa. Emerg Infect Dis, 1998; 4(3): 398-403

20. 20Usher PK. Modelling Malaria Transmission Potential for Climate Scenarios in West Africa and Europe. Earth Environ, 2010;5: 40-65.

21. Grover-Kopec EK, Blumenthal MB, Ceccato P, Dinku T, Omumbo JA, Connor SJ. Web-based climate information resources for malaria control in Africa. Malar J, 2006;5:38

22. Thomson MC, Connor SJ, D'alessandro U, et al. Predicting malaria infection in Gambian children from satellite data and bed net use surveys: the importance of spatial correlation in the interpretation of results. Am J Trop Med Hyg, 1999;61(1):2-8.

23. Deribew A, Alemseged F, Tessema F, et al. Malaria and under-nutrition: a community based study among under-five children at risk of malaria, south-west Ethiopia. PLoS ONE, 2010;5(5):e10775.

24. Yewhalaw D, Legesse W, Bortel WV , et al. Malaria and water resource development: the 
case of Gilgel-Gibe hydroelectric dam in Ethiopia Malar J, 2009;8:21.

25. Deribew A, Alemseged F, Birhanu Z, et al. Effect of training on the use of long-lasting insecticidetreated bed nets on the burden of malaria among vulnerable groups, south-west Ethiopia: baseline results of a cluster randomized trial. Malar $J$, 2010;9:121.

26. Jima D, Getachew A, Bilak H, et al. Malaria indicator survey 2007, Ethiopia: coverage and use of major malaria prevention and control interventions. Malar J, 2010;9:58.

27. Karunamoorthi K, Bekele M. Changes in Malaria Indices in an Ethiopian Health Centre: A Five Year Retrospective Analysis. Health Scope, 2012;1(3):118-26.

28. Sena LD, Deressa WA, Ali AA. Predictors of longlasting insecticide-treated bed net ownership and utilization: evidence from community-based crosssectional comparative study, Southwest Ethiopia. Malar J, 2013;12:406.

29. Deressa W, Olana D, Chibsa S. Community participation in malaria epidemic control in highland areas of southern Oromia, Ethiopia. Ethiop J Health Dev, 2005;19(1):3-10.

30. Pascual M, Cazelles B, Bouma MJ, Chaves LF, Koelle K. Shifting patterns: malaria dynamics and rainfall variability in an African highland. Proc $R$ Soc B, 2008;275:123-32.

31. Woyessa A, Deressa W, Ali A, Lindtjørn B. Malaria risk factors in Butajira area, south-central Ethiopia: a multilevel analysis. Malar $J$, 2013;12:273.

32. Githeko AK, Ndegwa W. Predicting malaria epidemics in the Kenyan highlands using climate data: a tool for decision makers. Global change and health, 2001;2(1):54-63.

33. Danuor SK, Tay SCK, Annor T, Forkuo EK, Bosompem KM, Antwi3 V, editors. The impact of climate variability on malaria incidence and prevalence in the forest zone of Ghana - A case study at two (2) hospitals located within the Kumasi Metropolitan area of the Ashanti Region of Ghana. 2nd International Conference: Climate, Sustainability and Development in Semi-arid Regions; 2010; August 16 - 20, 2010, Fortaleza Ceará, Brazil.

34. Wardrop NA, Barnett AG, Atkinson J-A, Clements AC. Plasmodium vivax malaria incidence over time and its association with temperature and rainfall in four counties of Yunnan Province, China. Malar J, $2013 ; 12: 452$.

35. Galardo AKR, Zimmerman RH, Lounibos LP, et al. Seasonal abundance of anopheline mosquitoes and their association with rainfall and malaria along the Matap'1 River, Amap'1. Brazil. Med Vet Entomol, 2009;23:335-49.

36. Meyrowitsch DW, Pedersen EM, Alifrangis M, et al. Is the current decline in malaria burden in subSaharan Africa due to a decrease in vector population? Malar J, 2011;10:188.

37. Omonijo AG, Matzarakis A, Oguntoke O, Adeofun CO. Influence of Weather and Climate on Malaria Occurrence Based on Human-Biometeorological Methods in Ondo State, Nigeria. Journal of Environmental Science and Engineering, 2011;5:1215-28.

38. Okanga S, Cumming GS, Hockey PA. Avian malaria prevalence and mosquito abundance in the Western Cape, South Africa. Malar J, 2013; 12:370

39. Briët OJ, Vounatsou P, Gunawardena DM, Galappaththy GN, Amerasinghe PH. Temporal correlation between malaria and rainfall in Sri Lanka. Malar J, 2008;7:77.

40. Thomson MC, Mason SJ, Phindela T, Connor SJ. Use of rainfall and sea surface temperature monitoring for malaria early warning in botswana. Am J Trop Med Hyg, 2005;73(1):214-21.

41. Peterson I, Borrell LN, El-Sadr W, Teklehaimanot A. A Temporal-Spatial Analysis of Malaria Transmission in Adama, Ethiopia. Am J Trop Med Hyg, 2009;81(6):944-9.

42. Alemu A, Muluye D, Mihret M, Adugna M, Gebeyaw M. Ten year trend analysis of malaria prevalence in Kola Diba, North Gondar, Northwest Ethiopia. Parasite Vectors, 2012;5:173.

43. Hui F-M, Xu B, Chen Z-W, et al. Spatio-Temporal Distribution of Malaria in Yunnan Province, China. Am J Trop Med Hyg, 2009;8(3):503-9.

44. Dhiman RC, Chavan L, Pant M, Pahwa S. National and regional impacts of climate change on malaria by 2030. Current Science, 2011;101(3):372-83.

45. Lowe R, Chirombo J, Tompkins AM. Relative importance of climatic, geographic and socioeconomic determinants of malaria in Malawi. Malar J, 2013;12:416.

46. Zhou G, Minakawa N, Githeko AK, Yan G. Climate variability and malaria epidemics in the highlands of East Africa. Trends Parasitol, 2005;21(2):54-6. 